\title{
Marital status independently predicts pancreatic cancer survival in patients treated with surgical resection: an analysis of the SEER database
}

\author{
Xiao-Dong Wang ${ }^{1}$, Jian-Jun Qian ${ }^{1}$, Dou-Sheng Bai ${ }^{1}$, Zhen-Nan Li ${ }^{1}$, Guo-Qing Jiang ${ }^{1}$ \\ and Jie Yao ${ }^{1}$ \\ ${ }^{1}$ Department of Hepatobiliary and Pancreatic Surgery, Clinical Medical College of Yangzhou University, Subei People's Hospital \\ of Jiangsu Province, Yangzhou, People's Republic of China
}

Correspondence to: Jie Yao, email: docyao@hotmail.com

Keywords: pancreatic cancer, marital status, SEER, survival analysis

Received: November 28, 2015 Accepted: March 07, $2016 \quad$ Published: March 29, 2016

\section{ABSTRACT}

Marital status is an independent prognostic factor for survival in several cancers. To determine if that is also true for pancreatic cancer after surgical treatment, we examined 13,370 cases of pancreatic cancer reported to the Surveillance, Epidemiology, and End Results (SEER) database between 1988 and 2012 . We found that patients who were widowed at the time of diagnosis were more likely to be female, a high percentage were elderly, a high ratio were diagnosed in early years, and a high proportion of tumors were located at the head of the pancreas $(P<$ $0.05)$. Marital status was confirmed to be an independent prognostic factor in both univariate and multivariate analyses $(P<0.05)$. In those with localized disease, 5 -year pancreatic cancer cause-specific survival was $6.5 \%$ lower in widowed patients than married ones (38.6\% vs. $32.1 \%)$, though this difference was not significant in a multivariate analysis $(P=\mathbf{0 . 0 8 4})$. In those with regional disease or distant metastasis, univariate and multivariate analyses indicated marital status to be an independent prognostic factor $(P<\mathbf{0 . 0 5})$. Thus marital status is an important prognostic factor in pancreatic cancer, and widowed patients are at greater risk of death than others.

\section{INTRODUCTION}

Pancreatic cancer is a devastating disease that remains the fourth leading cause of cancer-associated death in the United States [1, 2]. Despite advances in multi-modality therapy, pancreatic cancer remains extraordinarily lethal, with a 5-year overall survival rate of approximately $5 \%[1,3]$. There are, however, differences in patient survival related to the tumor's histology and its stage at diagnosis. Moreover, socioeconomic and demographic variables also likely play a role in the survival of pancreatic cancer patients, as has been demonstrated with other malignancies.

It is now recognized that marital status is a meaningful determinant of disease stage and grade at presentation, as well as a determinant of disease evolution after treatment. In colorectal cancer, for example, married individuals present with less advanced stage at diagnosis and exhibit better survival than unmarried individuals $[4$, 5]. Similarly, a larger population-based study of data from the Surveillance, Epidemiology and End Results (SEER) database indicates that for ten leading causes of cancerrelated death, unmarried patients are at significantly greater risk of presentation with metastatic cancer, undertreatment, and death resulting from their cancer [6]. Although the impact of marital status on pancreatic cancer survival has not been extensively studied, the available data suggest marital status is an independent prognostic factor for both perioperative and long-term survival in patients with pancreatic cancer [7]. In that study, however, only a relative small number of patients were treated surgically, and unmarried individuals were not differentiated based on whether they were single, divorced and widowed. Therefore, to further investigate the relationship between marital status and pancreatic cancer outcomes, as well as the potential underlying mechanisms, we used data from the SEER cancer registry to explore the impact of marital status on pancreatic cancer cause-specific survival (PCSS) in patients after surgical resection. 


\section{RESULTS}

\section{Patient characteristics}

There were 13,370 eligible cases (6,761 males and 6,609 females) of pancreatic adenocarcinoma reported in the SEER database from 1988 to 2012. Of those, 8,650 $(64.70 \%)$ were married, $1,765(13.20 \%)$ were widowed, $1,564(11.70 \%)$ were single, and $1391(10.40 \%)$ were divorced/separated. The median follow-up time was 22 months. The characteristics of patients with different marital statuses are summarized in Table 1. Significant $(P<0.001)$ parameters include the following. Patients
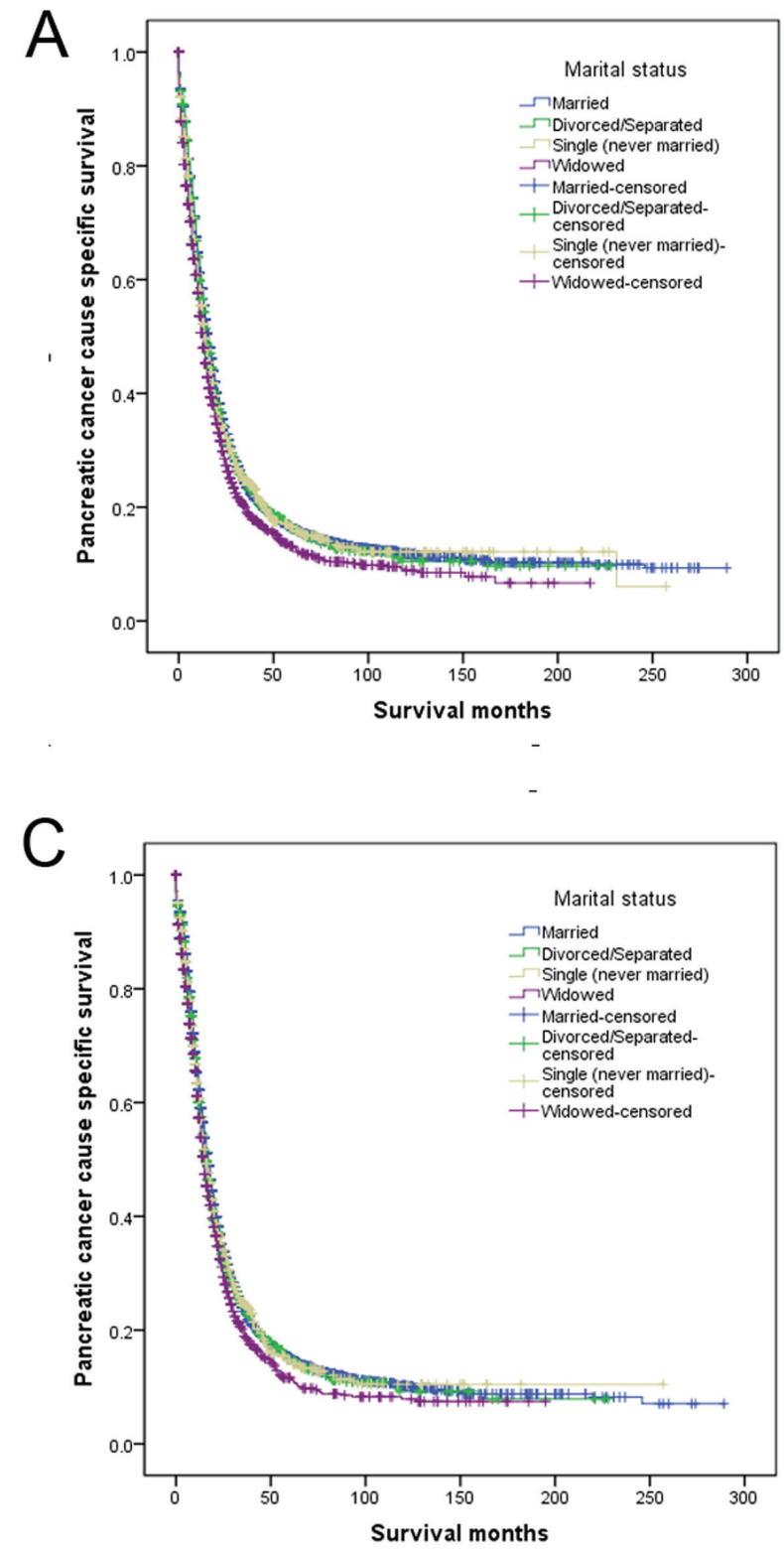

who were widowed at the time of diagnosis were more frequently female and a high percentage were elderly. In addition, a high ratio were diagnosed in early years, and a high proportion of the tumors were located at the head of the pancreas.

\section{Effect of marital status on PCSS}

Patients in the SEER database who were widowed at the time of diagnosis had poorer PCSS than patients who were single or divorced/separated for the first 5 years following diagnosis (Figure 1A). Married patients had an increased risk of pancreatic cancer-caused mortality (hazard ratio [HR] 1.140; confidence interval [95\% CI]
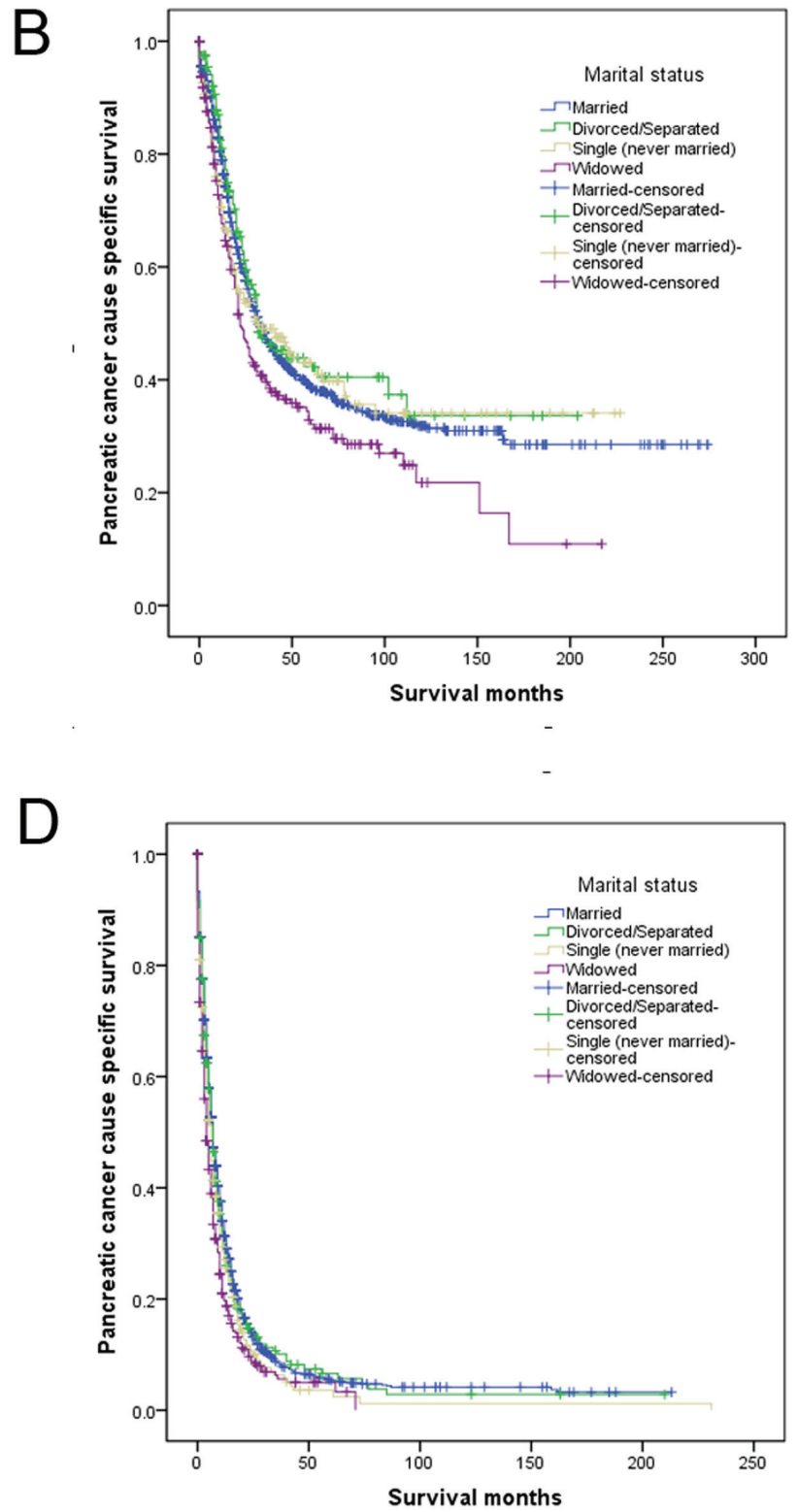

Figure 1 Survival curves in gastric patients according to marital status. a. All stage; $\chi^{2}=38.536, P<0.001$; b. Localized: $\chi^{2}=$ 9.572, $P=0.023$; c. Regional: $\chi^{2}=15.939, P=0.001$; d. Distant: $\chi^{2}=30.700, P<0.001$. 
Table 1: Baseline demographic and tumor characteristics of patients in SEER database.

\begin{tabular}{|c|c|c|c|c|c|c|}
\hline & Total & Married & $\begin{array}{l}\text { Divorced/ } \\
\text { Separated }\end{array}$ & Single & Widowed & $P$ value \\
\hline \multirow[t]{2}{*}{ Characteristic } & $(n=13370)$ & $(n=8650)$ & $(n=1391)$ & $(n=1564)$ & $(n=1765)$ & \\
\hline & & $N(\%)$ & $N(\%)$ & $N(\%)$ & $N(\%)$ & \\
\hline Sex & & & & & & $<0.001$ \\
\hline Male & 6761 & $5036(58.2)$ & $574(41.3)$ & $827(52.9)$ & $324(18.4)$ & \\
\hline Female & 6609 & $3614(41.8)$ & $817(58.7)$ & $737(47.1)$ & 1441(81.6) & \\
\hline Age & & & & & & $<0.001$ \\
\hline$\leqq 60$ & 4388 & $2874(33.2)$ & $583(41.9)$ & $802(51.3)$ & $129(7.3)$ & \\
\hline$>60$ & 8982 & $5776(66.8)$ & $808(58.1)$ & $762(48.7)$ & $1636(92.7)$ & \\
\hline Race & & & & & & $<0.001$ \\
\hline White & 10883 & $7247(83.8)$ & $1076(77.4)$ & $1115(71.3)$ & $1445(81.9)$ & \\
\hline Black & 1289 & $569(6.6)$ & $217(15.6)$ & $331(21.2)$ & $172(9.7)$ & \\
\hline Other* & 1169 & $816(9.4)$ & $95(6.8)$ & $113(7.2)$ & $145(8.2)$ & \\
\hline Unknown & 29 & $18(0.2)$ & $3(0.2)$ & $5(0.3)$ & $3(0.2)$ & \\
\hline \multicolumn{7}{|l|}{ Year of diagnosis } \\
\hline 1988-1996 & 2347 & $1504(17.4)$ & $226(16.2)$ & $238(15.2)$ & $379(21.5)$ & \\
\hline 1997-2005 & 5684 & $3698(42.8)$ & $565(40.6)$ & $659(42.1)$ & $762(43.2)$ & \\
\hline 2006-2012 & 5339 & $3448(39.9)$ & $600(43.1)$ & $667(42.6)$ & $624(35.4)$ & \\
\hline \multicolumn{7}{|l|}{$\begin{array}{l}\text { Primarysite } \\
\text { location }\end{array}$} \\
\hline Head & 9724 & $6272(72.5)$ & $1021(73.4)$ & $1164(74.4)$ & $1267(71.8)$ & \\
\hline Body & 724 & $492(5.7)$ & $62(4.5)$ & $73(4.7)$ & $97(5.5)$ & \\
\hline Tail & 1163 & $759(8.8)$ & $123(8.8)$ & $119(7.6)$ & $162(9.2)$ & \\
\hline Overlapping & 604 & $408(4.7)$ & $67(4.8)$ & $62(4.0)$ & $67(3.8)$ & \\
\hline Unspecific & 1155 & $719(8.3)$ & $118(8.5)$ & $146(9.3)$ & $172(9.7)$ & \\
\hline $\begin{array}{l}\text { Pathological } \\
\text { grading }\end{array}$ & & & & & & 0.054 \\
\hline $\mathrm{I} / \mathrm{II}$ & 7213 & $4675(54.0)$ & $742(53.3)$ & $829(53.0)$ & $967(54.8)$ & \\
\hline III/ IV & 4139 & $2722(31.5)$ & $439(31.6)$ & $471(30.1)$ & $507(28.7)$ & \\
\hline Unknown & 2018 & $1253(14.5)$ & $210(15.1)$ & $264(16.9)$ & $291(16.5)$ & \\
\hline Tumor Size $(\mathrm{cm})$ & & & & & & $<0.001$ \\
\hline$\leq 4$ & 8374 & $5453(63.0)$ & $887(63.8)$ & $953(60.9)$ & $1081(61.2)$ & \\
\hline$>4$ & 3081 & $2093(23.6)$ & $294(21.1)$ & $375(24.0)$ & $373(21.1)$ & \\
\hline Unknown & 1915 & $1158(13.4)$ & $210(15.1)$ & $236(15.1)$ & $311(17.6)$ & \\
\hline SEER stage & & & & & & 0.172 \\
\hline Localized & 1624 & $1040(12.0)$ & $158(11.4)$ & $204(13.0)$ & $222(12.6)$ & \\
\hline Regional & 9135 & $5941(68.7)$ & $979(70.4)$ & $1047(66.9)$ & $1168(66.2)$ & \\
\hline Distant & 2611 & $1669(19.3)$ & $254(18.3)$ & $313(20.0)$ & $375(21.2)$ & \\
\hline
\end{tabular}

*: Other includes American Indian/Alaska native, Asian/Pacific Islander, etc. 
Table 2: Univariate and multivariate survival analysis for evaluating the influence of marital status on pancreatic cancer cause-specific survival in SEER database.

\begin{tabular}{|c|c|c|c|c|c|}
\hline \multirow[b]{2}{*}{ Variable } & \multirow[b]{2}{*}{ 5-year CCS } & \multicolumn{2}{|c|}{ Univariate analysis } & \multicolumn{2}{|c|}{ Multivariate analysis } \\
\hline & & Log rank $\chi^{2}$ test & $\boldsymbol{P}$ & HR(95\%CI) & $P$ \\
\hline Sex & & 1.924 & 0.165 & & NI \\
\hline Male & $15.4 \%$ & & & & \\
\hline Female & $16.5 \%$ & & & & \\
\hline Age & & 72.907 & $<0.001$ & & $<0.001$ \\
\hline$\leqq 60$ & $18.4 \%$ & & & Reference & \\
\hline$>60$ & $14.7 \%$ & & & $1.262(1.208-1.318)$ & \\
\hline Race & & 9.218 & 0.010 & & 0.157 \\
\hline White & $15.9 \%$ & & & Reference & \\
\hline Black & $14.7 \%$ & & & $1.069(0.98-1.145)$ & 0.055 \\
\hline Other* & $18.2 \%$ & & & $1.00(0.931-1.074)$ & 0.999 \\
\hline Year of diagnosis & & 557.499 & $<0.001$ & & $<0.001$ \\
\hline 1988-1996 & $10.6 \%$ & & & Reference & \\
\hline $1997-2005$ & $13.5 \%$ & & & $0.834(0.791-0.879)$ & $<0.001$ \\
\hline 2006-2012 & $22.2 \%$ & & & $0.563(0.530-0.597)$ & $<0.001$ \\
\hline Primary site location & & 68.513 & $<0.001$ & & 0.001 \\
\hline Head & $15.9 \%$ & & & Reference & \\
\hline Body & $19.0 \%$ & & & $0.965(0.880-1.058)$ & 0.448 \\
\hline Tail & $18.5 \%$ & & & $0.902(0.837-0.973)$ & 0.008 \\
\hline Overlapping & $12.1 \%$ & & & $1.150(1.046-1.264)$ & 0.004 \\
\hline Unspecific & $14.1 \%$ & & & $1.009(0.938-1.085)$ & 0.805 \\
\hline Grade & & 300.500 & $<0.001$ & & $<0.001$ \\
\hline I / II & $19.0 \%$ & & & Reference & \\
\hline III/ IV & $10.9 \%$ & & & $1.402(1.341-1.465)$ & $<0.001$ \\
\hline Unknown & $15.0 \%$ & & & $1.156(1.089-1.227)$ & $<0.001$ \\
\hline Tumor Size(cm) & & 160.754 & $<0.001$ & & $<0.001$ \\
\hline$\leq 4$ & $18.5 \%$ & & & Reference & \\
\hline$>4$ & $13.8 \%$ & & & $1.227(1.167-1.290)$ & $<0.001$ \\
\hline Unknown & $8.3 \%$ & & & $1.437(1.352-1.528)$ & $<0.001$ \\
\hline SEER Stage & & 3309.783 & $<0.001$ & & $<0.001$ \\
\hline Localized & $38.6 \%$ & & & Reference & \\
\hline Regional & $14.7 \%$ & & & $1.890(1.760-2.029)$ & $<0.001$ \\
\hline Distant & $5.1 \%$ & & & $3.803(3.509-4.121)$ & $<0.001$ \\
\hline Marital Status & & 38.536 & $<0.001$ & & $<0.001$ \\
\hline Married & $16.4 \%$ & & & Reference & \\
\hline Divorced/Separated & $16.3 \%$ & & & $1.035(0.968-1.107)$ & 0.312 \\
\hline Never married & $16.6 \%$ & & & $1.112(1.042-1.186)$ & 0.001 \\
\hline Widowed & $13.1 \%$ & & & $1.140(1.073-1.211)$ & $<0.001$ \\
\hline
\end{tabular}

*: Other includes American Indian/Alaska native, Asian/Pacific Islander, and unknown.

NI: not included in the multivariate survival analysis. 
Table 3: Univariate and multivariate analysis of marital status on pancreatic cancer cause specific survival based on different cancer stage.

\begin{tabular}{|c|c|c|c|c|c|}
\hline \multirow[b]{2}{*}{ Variable } & \multirow[b]{2}{*}{ 5-year CCS } & \multicolumn{2}{|c|}{ Univariate analysis } & \multicolumn{2}{|c|}{ Multivariate analysis } \\
\hline & & Log $\operatorname{rank} \chi^{2}$ test & $\boldsymbol{P}$ & HR(95\%CI) & $P$ \\
\hline \multicolumn{6}{|l|}{ SEER Stage } \\
\hline \multicolumn{6}{|l|}{ Localized } \\
\hline Marital status & & 9.572 & 0.023 & & \\
\hline Married & $38.6 \%$ & & & Reference & \\
\hline Divorced/Separated & $42.3 \%$ & & & $1.048(0.819-1.340)$ & 0.710 \\
\hline Never married & $43.0 \%$ & & & $1.174(0.948-1.452)$ & 0.141 \\
\hline Widowed & $32.1 \%$ & & & $1.180(0.978-1.425)$ & 0.084 \\
\hline \multicolumn{6}{|l|}{ Regional } \\
\hline Marital status & & 15.939 & 0.001 & & \\
\hline Married & $15.3 \%$ & & & Reference & \\
\hline Divorced/separated & $14.8 \%$ & & & $1.050(0.970-1.137)$ & 0.229 \\
\hline Never married & $14.7 \%$ & & & $1.060(0.979-1.148)$ & 0.149 \\
\hline Widowed & $11.6 \%$ & & & $1.117(1.038-1.203)$ & 0.003 \\
\hline \multicolumn{6}{|l|}{ Distant } \\
\hline Marital status & & 30.700 & $<0.001$ & & \\
\hline Married & $5.3 \%$ & & & Reference & \\
\hline Divorced/separated & $6.6 \%$ & & & $1.004(0.868-1.161)$ & 0.961 \\
\hline Never married & $3.6 \%$ & & & $1.218(1.066-1.392)$ & 0.004 \\
\hline Widowed & $3.3 \%$ & & & $1.135(1.002-1.286)$ & 0.046 \\
\hline
\end{tabular}

$P$-values refer to comparisons between two groups and were adjusted for primary site location, age, race, year of diagnosis, pathological grading, and tumor size as covariates.

NI: not included in the multivariate survival analysis.

1.073-1.211), even after controlling for age at diagnosis, year of diagnosis, race/ethnicity, disease stage, and tumor type (Table 2).

Several other covariates were also predictive of mortality following surgical resection of pancreatic cancer. Older patients had poorer PCSS (HR 1.262; 95\% CI 1.208-1.318), while white patients had a lower risk of mortality than black patients (HR 1.069 ; 95\%CI 0.981.145). Patients diagnosed more recently experienced lower rates of pancreatic cancer-caused mortality (19972005, HR 0.834, 95\%CI 0.791-0.879; 2006-2012, HR 0.563 , 95\%CI 0.530-0.597). Unsurprisingly, presenting with poorer grade, larger tumor or advanced stage were highly predictive of cancer-specific mortality $(P<0.05)$ (Table 2).

\section{Subgroup analysis of the effect of marital status}

We next assessed of the effects of marital status on survival at each tumor stage. Among patients diagnosed with localized disease, 5-year PCSS was 6.5\% lower for widowed than married patients (38.6\% vs. 32.1\%), though this difference was not significant in a multivariate analysis $(P=0.084)$. For patients with regional disease or distant metastasis, marital status was an independent prognostic factor associated with survival in univariate and multivariate analyses $(P<0.05)$. On the other hand, there was no apparent difference between the divorced/ separated and married patients at any stage (Table 3, Figure 1B-1D).

\section{DISCUSSION}

Married persons enjoy better overall health and a longer life expectancy than unmarried ones [8-10]. Research also indicates there is a survival advantage for married persons living with a chronic disease such as cancer. Indeed, marital status is an independent prognostic factor associated with survival in several cancers [4-6, 11-14]. In the present study, we used the SEER database to address this issue in the context of pancreatic cancer. We found that widowed patients had significantly poorer PCSS than their married counterparts. Moreover, the disadvantage to widowed patients persisted, even after 
adjusting for age, race, tumor location, grade and stage in multivariable analyses.

In an earlier study, Baine et al. showed that marital status is an independent prognostic factor associated with both perioperative and long-term survival in patients with pancreatic cancer [7]. However, they treated unmarried patients as single group and also did not distinguish patients based on disease stage. Our study indicates that unmarried patients are in fact a heterogeneous group, and that widowed patients have poorer survival outcomes than other unmarried patients. However, when considering localized pancreatic cancer, the number of patients in the widowed group was small, which can make the effect of marital status on PCSS difficult to detect and/or to quantify. This appears to have been the case in our study, as marital status emerged as a statistically significant factor in univariate analyses, but not in multivariate models.

One hypothesis to explain the less favorable prognosis in unmarried individuals is delayed diagnosis with advanced tumor stage. In our study group, however, the percentages of patients with localized and regional tumors or distant metastasis were comparable among the four subgroups. And clearly delayed diagnosis cannot explain the poorer survival outcomes in widowed patients treated with surgical resection. More likely, the relationship between marital status and survival is explained by psychosocial factors that are independent of tumor characteristics and the extent of treatment. Psychologically, a cancer diagnosis can be more distressing than other diagnoses [15]. Patients who are married display less distress, depression, and anxiety than their unmarried counterparts, as a partner can share the emotional burden and provide appropriate social support [16]. Marital status may also affect adherence to medical recommendations, leading to better compliance with treatment, delivery of treatment at more highly recognized centers, and acceptance of more aggressive treatment, all of which may result in better cancer control [17]. In addition, DiMatteo et al. observed a strong relationship between depression and non-adherence, and married patients displayed a lower risk of major depression [18]. Consistent with those ideas, when women with depression are diagnosed with breast cancer, they undergo definitive treatment less often and show poorer survival [19].

There is also evidence that a lack of psychosocial support and psychological stress alters immune function and contributes to tumor progression and mortality [2022]. This may be made manifest by lower levels of natural killer cell activation, which may in turn lead to failure of cancer control [23]. Physicians should consider screening for depression among unmarried patients with cancer and refer patients to mental health specialists if symptoms are identified [6]. A widowed patient's loss of social support or their inability to cope with stress may lead to excess mortality [4, 24].

This study adds to current knowledge by answering in-depth questions about the relation between marital status and pancreatic cancer prognosis. However, it has several potential limitations. First, the marital status of a few patients did not stay the same, which could affect the results. Some patients classified as never married may have been cohabitating, while some patients classified as married may have separated or actually divorced. Second, the quality of the marriage can also impact the survival of pancreatic cancer patients. Marital distress has long term immune consequences and increases the risk of a variety of health problems [25]. Third, and perhaps most important, the SEER pancreatic cancer database lacks quality data on the surgery and systemic therapy. For example, the number of cycles or the chemotherapeutic regimen cannot be determined from the available data.

Despite these potential limitations, our results show that unmarried patients are a heterogeneous group, and that widowed patients are at a higher risk of death from their cancer than other patients. Psychosocial factors may be the primary reasons for the poorer survival outcomes in widowed patients. Physicians caring for these patients should be aware of their situation and provide closer care and interventions to help reduce their mortality risk.

\section{MATERIALS AND METHODS}

The SEER database was utilized to access processed publically available data in 18 registries acquired from 1988 to 2012. The demographic and incidence data collected by the SEER registries cover approximately 28 percent of the US population, which are considered to be representative of the US population as a whole. The database includes sensitive patient information and has been widely used for studies of the relationship between marital status and survival outcomes of patients with cancer $[6,11,13,14,26,27]$.

ICD-O-3 (International Classification of Diseases for Oncology, $3^{\text {rd }}$ edition) morphology codes 8000,8010 , $8140,8240,8246,8255,8260,8481,8480,8500$ and 8574 were used with SEER*Stat software version 8.1.5 to identify pancreatic cancer. The inclusion criteria were as follows: (a) known marital status; (b) had a single primary pancreatic cancer or had more than one primary cancer but the pancreatic cancer was the first; (c) age at diagnosis was older than 18 years; (d) received surgical resection; (e) the cause of death and the number of months survived were both known. All pancreatic subsites, including C25.0Head of pancreas, C25.1-Body of pancreas, and C25.2Tail of pancreas, C25.8-Overlapping lesion of pancreas, C25.3-Pancreatic duct and unspecific location information were included in the study. 


\section{Statistical analysis}

Factors including marital status, age, gender, race, tumor location, extent of disease and year of diagnosis were evaluated. Race was divided into white, black and others. According to the SEER staging system, tumors that remain in situ or confined to the organ or origin were regarded as localized. Those that locally invaded or metastasized to regional lymph nodes were considered to be regional, while those that traveled to distant organs were categorized as distant. Within the SEER database, the marital status of the patient was recorded at the time of diagnosis. Marital status was coded as married, divorced, widowed, separated, never married and unmarried or domestic partner. Individuals in the separated and divorced groups were clustered together as divorced/separated $[4,14]$, while never married and unmarried or domestic partner were grouped together.

Differences in the distribution of covariates according to marital status were assessed using two-sided $\chi 2$ tests. Differences in survival were assessed using twosided Kaplan-Meier log-rank tests. Multivariable Cox regression models were built for analysis of risk factors for survival outcomes. The primary endpoint of this study was PCSS, which was calculated from the date of diagnosis to the date of cancer-specific death. Deaths attributed to pancreatic cancer were treated as events, while deaths from other causes were treated as censored observations. All analyses were performed using the statistical software package SPSS for Windows, version 17 (SPSS Inc., Chicago, IL, USA). Statistically significance was set at two-sided $P<0.05$.

\section{ACKNOWLEDGMENTS}

The authors acknowledge the efforts of the Surveillance, Epidemiology, and End Results (SEER) Program tumor registries in the creation of the SEER database. The interpretation and reporting of these data are the sole responsibility of the authors.

This work was supported by National Natural Science Foundation of China (No.81272715).

\section{CONFLICTS OF INTEREST}

None of the authors have any conflict of interest to declare.

\section{REFERENCES}

1. Siegel RL, Miller KD and Jemal A. Cancer statistics, 2015. CA Cancer J Clin. 2015; 65:5-29.

2. Vincent A, Herman J, Schulick R, Hruban RH and Goggins M. Pancreatic cancer. Lancet. 2011; 378:607-620.

3. Raimondi S, Maisonneuve $\mathrm{P}$ and Lowenfels $\mathrm{AB}$.
Epidemiology of pancreatic cancer: an overview. Nat Rev Gastroenterol Hepatol. 2009; 6:699-708.

4. Li Q, Gan L, Liang L, Li X and Cai S. The influence of marital status on stage at diagnosis and survival of patients with colorectal cancer. Oncotarget. 2015; 6:7339-7347. doi: 10.18632/oncotarget.3129.

5. Johansen C, Schou G, Soll-Johanning H, Mellemgaard A and Lynge $\mathrm{E}$. Influence of marital status on survival from colon and rectal cancer in Denmark. Br J Cancer. 1996; 74:985-988.

6. Aizer AA, Chen MH, McCarthy EP, Mendu ML, Koo S, Wilhite TJ, Graham PL, Choueiri TK, Hoffman KE, Martin NE, Hu JC and Nguyen PL. Marital status and survival in patients with cancer. J Clin Oncol. 2013; 31:3869-3876.

7. Baine M, Sahak F, Lin C, Chakraborty S, Lyden E and Batra SK. Marital status and survival in pancreatic cancer patients: a SEER based analysis. PLoS One. 2011; 6:e21052.

8. Kaplan RM and Kronick RG. Marital status and longevity in the United States population. J Epidemiol Community Health. 2006; 60:760-765.

9. Hu YR and Goldman N. Mortality differentials by marital status: an international comparison. Demography. 1990; 27:233-250.

10. Ikeda A, Iso H, Toyoshima H, Fujino $\mathrm{Y}$, Mizoue $\mathrm{T}$, Yoshimura T, Inaba Y, Tamakoshi A and Group JS. Marital status and mortality among Japanese men and women: the Japan Collaborative Cohort Study. BMC Public Health. 2007; 7:73.

11. Denberg TD, Beaty BL, Kim FJ and Steiner JF. Marriage and ethnicity predict treatment in localized prostate carcinoma. Cancer. 2005; 103:1819-1825.

12. Torssander $\mathrm{J}$ and Erikson R. Marital partner and mortality: the effects of the social positions of both spouses. J Epidemiol Community Health. 2009; 63:992-998.

13. Nelles JL, Joseph SA and Konety BR. The impact of marriage on bladder cancer mortality. Urol Oncol. 2009; 27:263-267.

14. Wang L, Wilson SE, Stewart DB and Hollenbeak CS. Marital status and colon cancer outcomes in US Surveillance, Epidemiology and End Results registries: does marriage affect cancer survival by gender and stage? Cancer Epidemiol. 2011; 35:417-422.

15. Kaiser NC, Hartoonian N and Owen JE. Toward a cancerspecific model of psychological distress: population data from the 2003-2005 National Health Interview Surveys. J Cancer Surviv. 2010; 4:291-302.

16. Goldzweig G, Andritsch E, Hubert A, Brenner B, Walach $\mathrm{N}$, Perry S and Baider L. Psychological distress among male patients and male spouses: what do oncologists need to know? Ann Oncol. 2010; 21:877-883.

17. Iwashyna TJ and Christakis NA. Marriage, widowhood, and health-care use. Soc Sci Med. 2003; 57:2137-2147.

18. DiMatteo MR, Lepper HS and Croghan TW. Depression 
is a risk factor for noncompliance with medical treatment: meta-analysis of the effects of anxiety and depression on patient adherence. Arch Intern Med. 2000; 160:2101-2107.

19. Goodwin JS, Zhang DD and Ostir GV. Effect of depression on diagnosis, treatment, and survival of older women with breast cancer. J Am Geriatr Soc. 2004; 52:106-111.

20. Garssen B and Goodkin K. On the role of immunological factors as mediators between psychosocial factors and cancer progression. Psychiatry Res. 1999; 85:51-61.

21. Sklar LS and Anisman H. Stress and coping factors influence tumor growth. Science. 1979; 205:513-515.

22. Moreno-Smith M, Lutgendorf SK and Sood AK. Impact of stress on cancer metastasis. Future Oncol. 2010; 6:18631881.

23. Antoni MH, Lutgendorf SK, Cole SW, Dhabhar FS, Sephton SE, McDonald PG, Stefanek M and Sood AK. The influence of bio-behavioural factors on tumour biology: pathways and mechanisms. Nat Rev Cancer. 2006; 6:240-
248.

24. Martikainen P and Valkonen T. Mortality after the death of a spouse: rates and causes of death in a large Finnish cohort. Am J Public Health. 1996; 86:1087-1093.

25. Jaremka LM, Glaser R, Malarkey WB and Kiecolt-Glaser JK. Marital distress prospectively predicts poorer cellular immune function. Psychoneuroendocrinology. 2013; 38:2713-2719.

26. Kravdal $\mathrm{H}$ and Syse A. Changes over time in the effect of marital status on cancer survival. BMC Public Health. 2011; 11:804.

27. Rippentrop JM, Joslyn SA and Konety BR. Squamous cell carcinoma of the penis: evaluation of data from the surveillance, epidemiology, and end results program. Cancer. 2004; 101:1357-1363. 